The authors state that all the patients with the postviral fatigue syndrome had characteristic mitochondrial changes, and some had RNA enteroviral sequences, but as the necessary investigations were not applied to the depressed patients or controls it is not possible to tell whether these findings did in fact distinguish the group with the syndrome.

Another issue that concerns us is that the authors fail to refer to the considerable body of work suggesting that release of prolactin mediated by 5 -hydroxytryptamine is suppressed in depressed patients ${ }^{3+}$ and that this response is enhanced by antidepressant treatments, including electroconvulsive therapy. ${ }^{5}$ There is a non-significant trend in their study for the depressed patients to have a smaller rise in prolactin secretion than controls, with the patients with the postviral fatigue syndrome having a significantly higher response than that of both the other groups. The finding that the prolactin response seems to be changed in opposite directions in the postviral fatigue syndrome and depression is of particular interest but makes it all the more frustrating that the clinical features of the two groups are not described more fully. Differences in neuroendocrine responses raise the possibility of subdividing poorly defined disease entities in a way that may better reflect underlying neuroendocrine disease, but to capitalise on this we need to know more about the correlations between these responses and individual symptoms.

DAVID CURTIS TIMOTHY BULLOCK

Academic Department of Psychiatry,

St Mary's Hospital,

London W2 $1 \mathrm{NY}$

1 Bakheit AMO, Behan PO, Dinan TG, Gray CE, O'Keane V' Possible upregulation of hypothalamic 5-hydroxytryptamin receptors in patients with postviral fatigue syndrome. $B M J$ 1992;304:1010-2. (18 April.)

2 American Psychiatric Association. Diagnostic and statistical manual of mental disorders, third edition, revised. Washington, DC: APA, 1987

3 Mitchell P, Smythe G. Hormonal responses to fenfluramine in depressed and control subjects. F Affective Disord 1990;19: depressed.

4 Anderson IM, Ware CJ, de Roza Davis JM, Cowan PJ. Decreased SHT-mediated prolactin release in major depression. Br f Psvchiatry 1992;160:372-8.

5 Shapira B, Lerer B, Kindler S, Lichtenberg P, Gropp C, Coope $\mathrm{T}$, et al. Enhanced serotonergic responsivity following electroconvulsive therapy in patients with major depression. BrF Psychiatry 1992;160:223-9.

AUTHOR'S REPLY, --In response to Simon Hatcher, all three groups in our study had baseline prolactin concentrations that did not differ significantly from each other. The high mean value in patients with the postviral fatigue syndrome did not represent odd high cases: this is a finding seen in severa studies. The reason for suggested high baseline prolactin concentrations is unknown.

As J S Bevan will know, buspirone has more than one action. Some data suggest that it acts as a dopamine antagonist.' Clearly, further experiments, which are under way, are necessary for a complete understanding of its mechanisms.

David Curtis and Timothy Bullock raise many issues. We emphasise that $20-30 \%$ of our series of patients with the postviral fatigue syndrome have no depression whatsoever and complain predominantly of fatigue and myalgia. When depression occurs it differs clinically from severe endogenous depression in that the patients do not experience guilt or delusions, are well able to enjoy themselves, and have no loss of interest and, usually, normal libido. Though they may have depressed mood, more usually their severe emotional lability is to the fore and is often the conspicuous symptom.

For research purposes we select patients whose illness occurs after a well defined viral illness and in whom the myalgia is so severe that occasionally they have been referred for cardiologists if the pain resembles that of a myocardial infarct. This highlights muscle involvement. We did not carry out muscle biopsies on depressed patients because we believe that this would not be ethical. We are well aware of the decreased release of prolactin mediated by 5 -hydroxytryptamine in major depression. ${ }^{2}$ The many studies quoted in this paper confirm the decreased response and tend to support our conclusion. Depression and fatigue occur quite commonly in disorders such as idiopathic cyclic oedema, multiple sclerosis, and Parkinson's disease, but these disorders are not primarily depressive illness. The depression in the postviral fatigue syndrome is only one of its symptoms.

Department of Neurology,
Southern General Hospital,

Glasgow G51 4TF

1 McMillen BA, Matthews RT, Sanghera MK, Shepherd PD, German DC. Dopamine receptor antagonism by the nove antianxiety drug buspirone. $\mathcal{F}$ Neurosci $1983 ; 3: 733-8$.

Anderson IM, Ware CJ, Davis JMDR, Cowan PJ. Decreased 5HT-mediated prolactin release in major depression. $\mathrm{Br}$ Psychiatry 1992;100:372-8.

EDIToR,-A M O Bakheit and colleagues recently reported ${ }^{1}$ a possible upregulation of hypothalamic 5-hydroxytryptamine receptors in patients with the postviral fatigue syndrome, giving some evi dence for hypothalamic functional abnormalities in these patients, which are different from others with depression. There is a growing body of evidence which claims that this clinical condition is organic and cannot be simply perceived as a somatisation disorder in patients with predisposition to psychiatric disease.

We reviewed and quantitatively analysed with Ceretec and single photon emission tomography the brain perfusion of 14 patients fulfilling the Oxford criteria for diagnosis of myalgic encephalomyelitis. ${ }^{3}$ They had all had disease for more than six months (more than half the time) manifested with generalised malaise and myalgia, as well as significant physical and intellectual disability. None had any medical condition known to produce fatigue or had recently or in the past had psychiatric disease.

When compared with a group of 24 nondepressed age and sex matched controls (norma volunteers) there was significant reduction of the perfusion to several areas of the brain cortex but particularly the brain stem (table). This original

Brain stem perfusion (mean $(S D)$ ) normalised to cerebellum and to visual cortex in 14 patients with myalgic encephalomyelitis and 24 controls

\begin{tabular}{|c|c|c|}
\hline Normalisation area & $\begin{array}{l}\text { Patients with myalgic } \\
\text { encephalomyelitis }\end{array}$ & Controls \\
\hline Cerebellum & $0.74(0.04)^{\star}$ & $0.80(0.04$ \\
\hline Visual cortex & $0.75(0.05)^{\star}$ & $0.84(0.05$ \\
\hline
\end{tabular}

$\mathrm{p}<0 \cdot 001$, Student's $t$ test for independent samples.

finding confirms that single photon emission tomography with Ceretec is an important tool for investigating patients with myalgic encephalomyelitis, including the chronic fatigue syndrome and the postviral fatigue'syndrome. This is the first observation of an organic component of this disease with significant deficits in brain perfusion, particularly in the hypothalamus and pons.

D C COSTA

J BROSTOFF

V DOUL

Institute of Nuclear Medicine and

P J ELL

Department of Immunology,

University College and Middlesex School

of Medicine,

London WIN 8AA

1 Bakheit AMO, Behan PO, Dinan TG, Gray CE, O'Keane Possible upregulation of hypothalamic 5-hydroxytryptamin Possible upregulation of hypothalamic 5-hydroxytryptamine
receptors in patients with postviral fatigue syndrome. $B M \mathcal{F}$ receptors in patients with post
1992;304:1010-2. (18 April.)
Cluff E. Medical aspects of delayed convalescence. Rev Infect Dis 1991;13:138-40.

3 Sharpe MC, Archard LC, Banatvala JE, Borysiewicz LK, Clare AW, David A, et al. A report-chronic fatigue syndrome guidelines for research. $\mathcal{F} R$ Soc Med 1991;84:118-21.

\section{Managing tuberculosis and HIV infection}

EDITOR, - The British Thoracic Society's guidelines on managing tuberculosis and HIV infection are incomplete and contain some points that clinicians who look after people infected with HIV with or without tuberculosis would take issue with. Data that I and a colleague obtained in a retrospective study of nine patients with HIV infection (five English with BCG scars, three Africans and one Indian who had had BCG vaccination but did not have a scar) showed that previous BCG vaccination does not protect people with HIV infection from developing tuberculosis. ${ }^{2}$ This should be another strong reason for not vaccinating such people, whatever their immune status. Normal chest radiographs in such people presenting with fever either with or without cough are well reported, ${ }^{23}$ and induction of sputum with hypertonic saline in patients unable to produce sputum is an important aid to diagnosis apart from invasive procedures such as bronchoscopy with bronchoalveolar lavage and biopsy.

Clinicians should also bear in mind that ethambutol should be included in the initial treatment regimen if central nervous system disease or disseminated disease is present or resistance to isoniazid is suspected. ${ }^{+}$Lifelong chemoprophylaxis with isoniazid after completion of treatment is controversial and, on the basis of current evidence, should be judged on each patient's clinical circumstances. As tuberculosis can be one of the earliest infections to occur in the course of HIV infection, such people should not be universally subjected to chemoprophylaxis with isoniazid throughout the time that they are still immunocompetent. Regular clinical monitoring may be more appropriate until more data are available as the guidelines acknowledge that reactions to antituberculous drugs are commoner in HIV positive people and desensitisation with steroid cover may be considered in difficult cases. ${ }^{6}$

Tuberculosis in people with HIV infection is an important public health issue in the United Kingdom as it is one of the few diseases that can be infectious to both HIV negative and HIV positive contacts and has a good outcome if treated appropriately.

Infectious Diseases Unit,

Department of Medicine

Newcastle General Hospital,

Newcastle upon Tyne NE4 6BE

1 Subcommittee of the Joint Tuberculosis Committee of the British Thoracic Society. Guidelines on the management of tuberThoracic Society. Guidelines on the management of tuber-
culosis and HIV infection in the United Kingdom. $B M \mathcal{F}$ 1992;304:1231-3. (9 May)

2 Ong ELC, Mandal BK. Tuberculosis in patients infected with the human immunodeficiency virus. Q F Med 1991;291:613-7. 3 Pedro-Botet J, Gutierrez J, Miralles R, Coll J, Rubies-Prat J. Pulmonary tuberculosis in HIV-infected patients with normal chest radiographs. AIDS 1992;6:91-3.

4 American Thoracic Society. Mycobacterioses and the acquired immunodeficiency syndrome. Am Rev Respir Dis 1987;136: $492-6$

5 Barnes PF, Bloch AB, Davidson PT, Snider DE. Tuberculosis in patients with human immunodeficiency virus infection. N Engl f Med 1991;324:1644-50.

6 Ong ELC, Mandal BK. Multiple drug reactions in a patient with AIDS. Lancet 1989;ii:976-7.

EDITOR,-Effective surveillance of tuberculosis is required to monitor the effectiveness of the recent guidelines on the management of tuberculosis and HIV infection' and reassure those responsible for controlling infection that in the United Kingdom 